\title{
Statistical Investigation on the Hydrolysis and Fermentation Processes of Cassava Peels in the Production of Bioethanol
}

\author{
Adenomon Monday Osagie ${ }^{1}$, Evans Patience Ogheneofejiro ${ }^{2}$, Tela Musa $\mathrm{Nma}^{3}$ \\ ${ }^{1}$ Statistics Unit, Department of Mathematical Sciences, Nasarawa State University, Keffi, Nigeria \\ ${ }^{2}$ Department of Mathematics, The Federal Polytechnic, Bida, Nigeria \\ ${ }^{3}$ Department of Statistics, The Federal Polytechnic, Bida, Nigeria
}

Email address:

admonsagie@gmail.com (A. M. Osagie)

To cite this article:

Adenomon Monday Osagie, Evans Patience Ogheneofejiro, Tela Musa Nma. Statistical Investigation on the Hydrolysis and Fermentation Processes of Cassava Peels in the Production of Bioethanol. International Journal of Statistical Distributions and Applications. Vol. 3, No. 3, 2017, pp. 47-55. doi: 10.11648/j.jijsd.20170303.14

Received: March 14, 2017; Accepted: April 17, 2017; Published: October 31, 2017

\begin{abstract}
There are several types of experiments which require statistical investigation. These are characterized by the nature of treatments under investigation and also the nature of comparison required among them so as to meet the objectives of the experiment. To achieve this, cassava peels was collected from Kasuwa Gwari market Minna, Niger state dried and taken for hydrolysis and fermentation processes. Temperature, acid concentration, cassava biomass ratio, ph and time were varied to get the optimum yield of reducing sugar. Curve fitting and a two-way analysis of variance were used in analyzing the data. Most of the results from the experiment follows quadratic model. Furthermore, time and temperature were very significant in both hydrolysis and fermentation processes. We therefore concluded that for hydrolysis process yield is optimum at $110^{\circ} \mathrm{C}$ and $30 \mathrm{mins}$, while for fermentation process yield is optimum at $35^{\circ} \mathrm{C}$ and at 6 days and 7 days respectively.
\end{abstract}

Keywords: Statistical Investigation, Hydrolysis, Fermentation, Processes, Cassava, Production, Bioethanol

\section{Introduction}

In African, Cassava is the third largest source of carbohydrate in food for human comsuption in the world [1]. That is why cassava (also known as Manihot esculenta crantz) is highly cultivated in African and in Nigeria in particular. In addition, cassava roots plays important role in African diet and are processed using simple methods. For instance, in Nigeria cassava can be processed to produce Gari, Fufu and Lafun floor [1]. Since cassava is in abundant in Nigeria, many times the cassava peels are wasted or converted to animal feeds.

Cassava peels contains high level of hydrogen cyanide, this toxic compound is remove by drying the peel under the sun in order to make it suitable for animal feeds [2]. Also researchers have found that cassava peel has some element of Bioethanol inherent in it.

Bioethanol is being considered as a potential liquid fuel due to the limited amount of natural resources [3]. And such bioethanol can be found in non-food waste, such as cassava peel. But this present work focused on statistical investigation of the processing of producing bioethanol from cassava peel.

There are several types of experiments which require statistical investigation. These are characterized by the nature of treatments under investigation and also the nature of comparison required among them so as to meet the objectives of the experiment [4].

Curve fitting is the process of constructing a curve, or mathematical function, that has the best fit to a series of data points, possibly subject to constraints. Curve fitting can involve either interpolation, where an exact fit to the data is required, or smoothing, in which a "smooth" function is constructed that approximately fits the data. Fitted curves can be used as an aid for data visualization, to infer values of a function where no data are available, and to summarize the 
relationships among two or more variables [5]. In addition, Curve fitting, also known as regression analysis, is used to find the "best fit" line or curve for a series of data points. Most of the time, the curve fit will produce an equation that can be used to find points anywhere along the curve [6].

On the other hand, the classical two-way analysis of variance (ANOVA) model is where one factor is the main focus of the study (which will be referred to as the main treatment factor) and the other factor is not of primary interest such as a block effect (which will be refer to as the secondary factor) [7-8].

In this present work, curve fitting Techniques and Twoway Analysis of variance will be applied to data collected during the hydrolysis and fermentation processes of the cassava peels in the production of Bioethanol.

\section{Literature Review}

[1] examined the ethanol production by saccharomyces cerevisiac from cassava peel hydrolysate. Their result revealed that the cassava peel hydrolysate with saccharomyces cerevisiac resulted in maximal ethanol production after three days.

[3] carried out a comparative study of bioethanol production from cassava peels by monoculture and co-culture of yeast. Their result revealed that cassava peel can produce high yields of ethanol.

[9] investigated the ethanol production capabilities of axenic cultures of saccharomyces cerevisiae and Escherichie coli from cassava waste water. The study revealed that the isolates had the ability of ethanol production from cassava waste water.

[10] they studied the feasibility of using non-food parts of cassava for energy production. They found that the potential use of cassava peel can led to the production of ethanol.

[11] considered enzymatic production of ethanol from cassava starch using two strains of saccharomyces cerevisiae. The yield of ethanol was found to vary but the highest ethanol concentration obtained was $5.3 \%$ at $10 \%$ initial sugar concentration, which gave a sugar conversion efficiency of $37.3 \%$.

[12] examined the enzymatic production of bioethanol from cassava and sweet potato peels using two groups of organisms. The study revealed that bioethanol can be produced from cassava and sweet potato peels.

[13] they studied producing fermentable sugars by pretreatment and hydrolysis of cassava peels using Aspergillus niger and the crude enzymes. They reported the potentials of cassava peels in reducing sugar production.

[14] studied to determine the optimum concentration of $\mathrm{H}_{2} \mathrm{SO}_{4}$ and optimum time in the hydrolysis process and determine the optimum time in the fermentation time. The result revealed that the optimum production was $0.5 \mathrm{M}$, $100^{\circ} \mathrm{C}, 4$ days and produced $3.58 \% \mathrm{v} / \mathrm{v}$ bioethanol.

[15] considered the production of bioethanol as an alternative source of fuel using cassava and yam peels as raw materials. The study revealed that bioethanol can be produced from cassava and yam peels with maximum yield from cassava peels.

[2] studied the ethanol production from cassava waste (pulp and peel) using alcohol tolerant yeast isolated from palm wine. The study revealed that ethanol produced from cassava pulp is higher than ethanol produced from cassava peel.

[16] investigated the potential of bioethanol production from cassava peels using different microbial inoculants simultaneously. The yield reported in the study competes favourably with those reported from cassava peels, potato peels and millet husks using other inoculant treatments by other researcher.

\section{Model specification}

\subsection{Curve Fitting Techniques (Least Squares Curve Fits)}

Least Squares is a method of curve fitting that has been popular for a long time. Least Squares minimizes the square of the error between the original data and the values predicted by the equation. While this technique may not be the most statistically robust method of fitting a function to a data set, it has the advantage of being relatively simple (in terms of required computing power) and of being well understood [17].

The following curve fits were adopted in this research work and the R-square criterion and the significant of the parameters will be used to choose the best fit that well describes the process. The curve fits will only be stated. They are found in SPSS 13.0 for windows. The following are the models for curve fitting:

(i). Linear: $Y=b_{0}+b_{1} t$

(ii). Quadratic: $Y=b_{o}+b_{1} t+b_{2} t^{2}$

(iii). Compound: $\ln Y=\ln b_{o}+\ln b_{1} t$

(iv). Growth: $\ln Y=b_{0}+b_{1} t$

(v). Logarithmic: $Y=b_{o}+b_{1} \ln t$

(vi). Cubic: $Y=b_{0}+b_{1} t+b_{2} t^{2}+b_{3} t^{3}$

(vii). $S: \ln Y=b_{o}+b_{1}(1 / t)$

(viii). Exponential: $\ln Y=\ln b_{o}+b_{1} t$

(ix). Inverse: $\mathrm{Y}=\mathrm{b}_{\mathrm{o}}+\mathrm{b}_{1}(1 / \mathrm{t})$

(x). Power: $\ln Y=\ln b_{o}+b_{1} \ln t$

(xi). Logistic: $\ln (1 / Y-1 / u)=\ln b_{o}+\ln b_{1} t$ where $u$ is the upper boundary value.

\subsection{Two Factor Without Interaction Analysis of Variance (Two-Way ANOVA)}

If there is no interaction between the two factors, then one can fit the model $Y_{i j k}=\mu+\alpha_{i}+\beta_{j}+\varepsilon_{i j k}$ Where $\mu=$ the overall mean; $\alpha_{i}=$ the main effect of the $i^{\text {th }}$ level of Factor A;

$\beta_{\mathrm{j}}=$ the main effect of the $\mathrm{j}^{\text {th }}$ level of Factor $\mathrm{B} ; \varepsilon_{\mathrm{ijk}}=$ the random error associated with $\mathrm{Y}_{\mathrm{ijk}}[18]$. 
Table 1. ANOVA table for the Two-way analysis of Variance.

\begin{tabular}{lllll}
\hline Source of variance & df & Sum of squares & Mean squares & F \\
\hline Blocks & $\mathrm{b}-1$ & $\sum \mathrm{B}_{\mathrm{i}}^{2} / \mathrm{t}-\mathrm{G}^{2} / \mathrm{N}=\mathrm{SS}_{\mathrm{B}}$ & $\mathrm{SS}_{\mathrm{B}} /(\mathrm{b}-1)=\mathrm{MS}_{\mathrm{B}}$ & $\mathrm{MS}_{\mathrm{B}} / \mathrm{MS}_{\mathrm{E}}$ \\
Treatment & $\mathrm{t}-1$ & $\sum \mathrm{T}_{\mathrm{i}}^{2} / \mathrm{t}-\mathrm{G}^{2} / \mathrm{N}=\mathrm{SS}_{\mathrm{T}}$ & $\mathrm{SS}_{\mathrm{T}} /(\mathrm{t}-1)=\mathrm{MS}_{\mathrm{T}}$ & $\mathrm{MS}_{\mathrm{T}} / \mathrm{MS}_{\mathrm{E}}$ \\
Error & $(\mathrm{b}-1)(\mathrm{t}-1)$ & $\mathrm{By}$ Substraction=SS & $\mathrm{SS}_{\mathrm{E}} /(\mathrm{b}-1)(\mathrm{t}-1)=\mathrm{MS}_{\mathrm{E}}$ & \\
Total & $\mathrm{bt}-1$ & & \\
\hline
\end{tabular}

We reject $\mathrm{H}_{0}$ if $\mathrm{F}_{\text {cal }}>\mathrm{F}_{\text {tab. }}$. The Duncan Multiple Range Test (DMRT) was use for Post ANOVA comparison [19] \& [20].

\section{Materials and Methods}

Cassava peel waste was collected from Kasuwa Gwari market Minna Niger State. The sample was air dried for three days before taking it to the National Cereals Research Institute, Badeggi. Bida, Niger State. The dried samples of cassava peel were milled to make it ready for further analysis. Temperature, Acid Concentration, Substrate concentration and time were varied for hydrolysis process. Also $\mathrm{pH}$, Temperature, Yeast
Concentration, Glucose concentration and time were varied for fermentation process. Lastly time with temperature were varied for hydrolysis and fermentation processes.

\section{Analysis and Results}

MINITAB and SPSS 13.0 version software were used for the analysis. We present the results in the following headings.

\subsection{Hydrolysis Process}

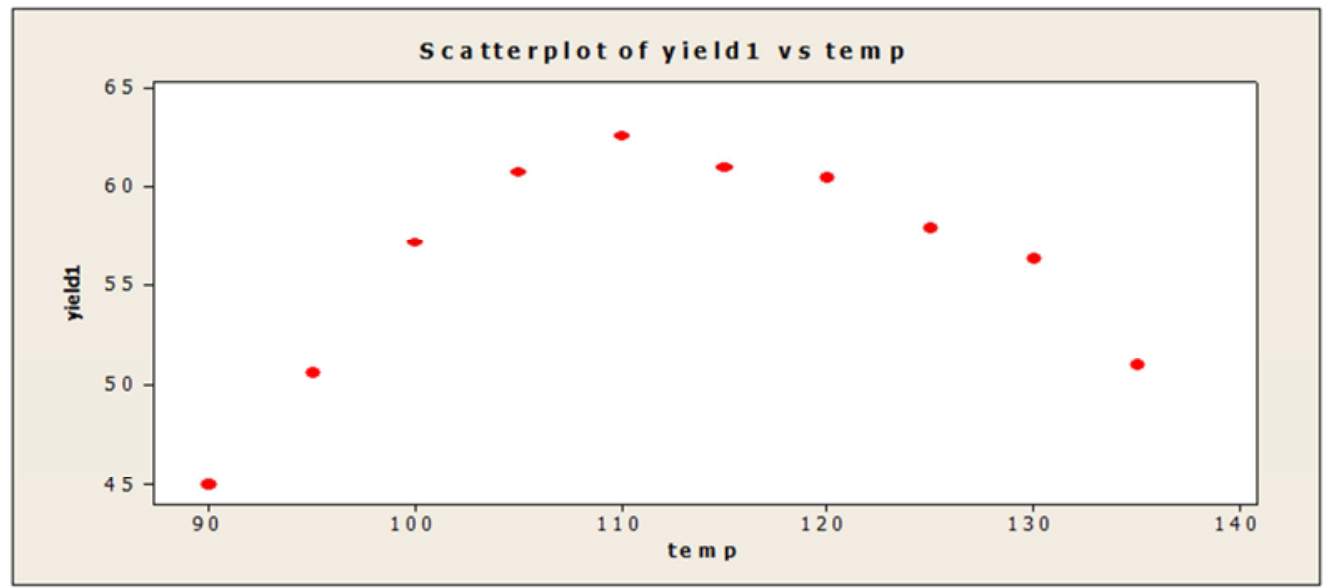

Figure 1. Temperature variation with glucose yield.

Yield $=-302.942+6.372$ temp +0.028 temp $^{\wedge} 2 \mathrm{R}^{2}=0.971$

t-values (-12.549) (14.680) (-14.434)

Interpretation: The relationship is explained by a quadratic model

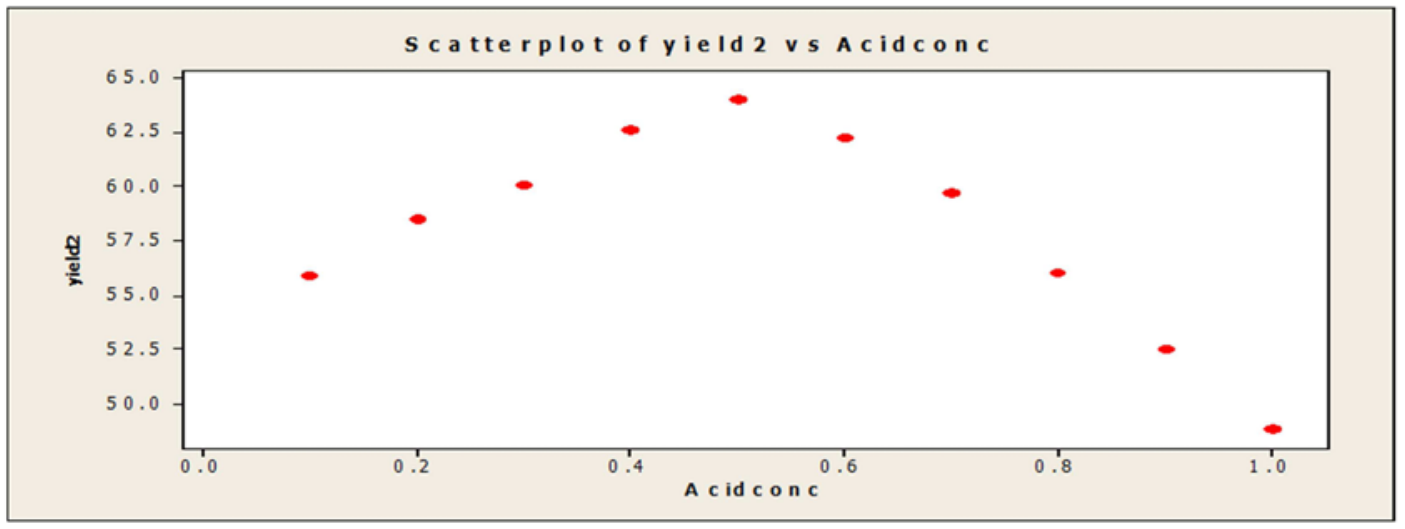

Figure 2. Acid concentration variation with yield.

Yield $=51.127+49.036$ Aidconc -52.121 Aidconc $^{\wedge} 2 \mathrm{R}^{2}=0.974$

t-values (49.443) (11.355) (-13.622)

Interpretation: The relationship is explained by a quadratic model 


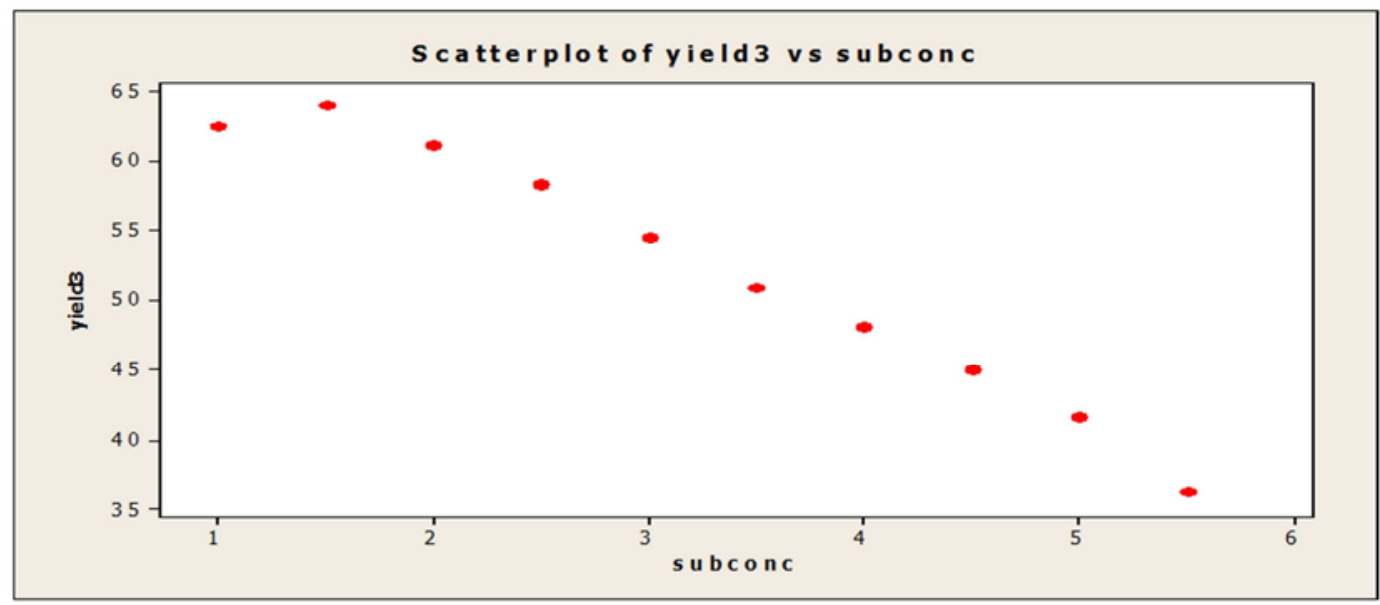

Figure 3. Substrate concentration variation with yield.

Yield $=72.190-6.154$ subconc $\mathrm{R}^{2}=0.972$

t-values (54.776) (16.591)

Interpretation: The relationship is explained by a Linear model

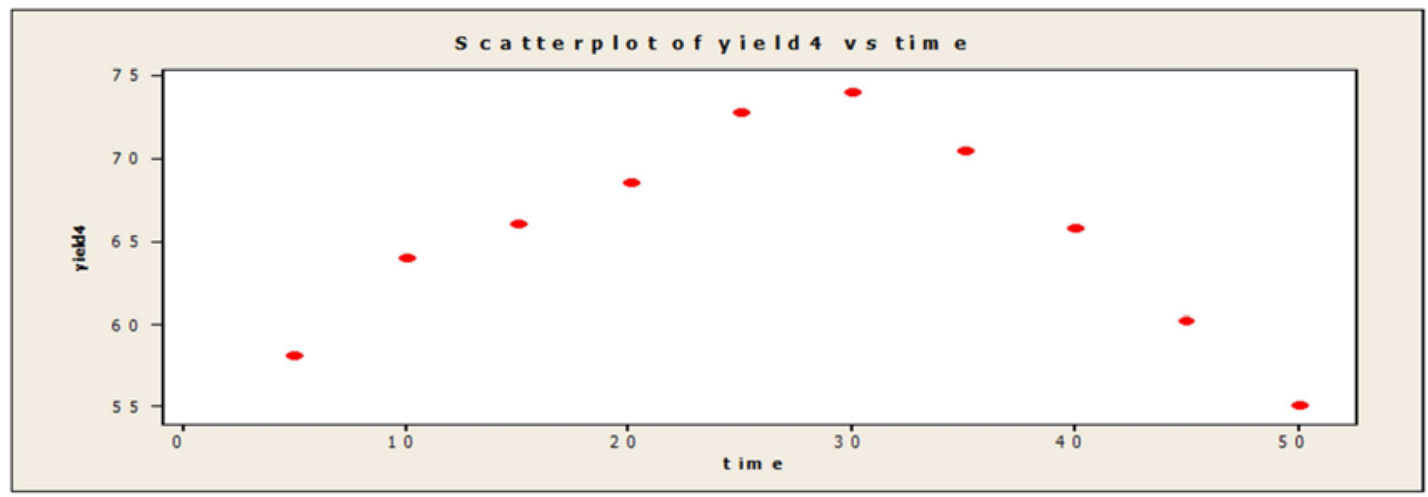

Figure 4. Time variation with yield.

Yield $=49.708+1.680$ time -0.032 time $^{\wedge} 2 \mathrm{R}^{2}=0.952$

t-values (27.032) (10.939) (-11.618)

Interpretation: The relationship is explained by a quadratic model

\subsection{Fermentation Process}

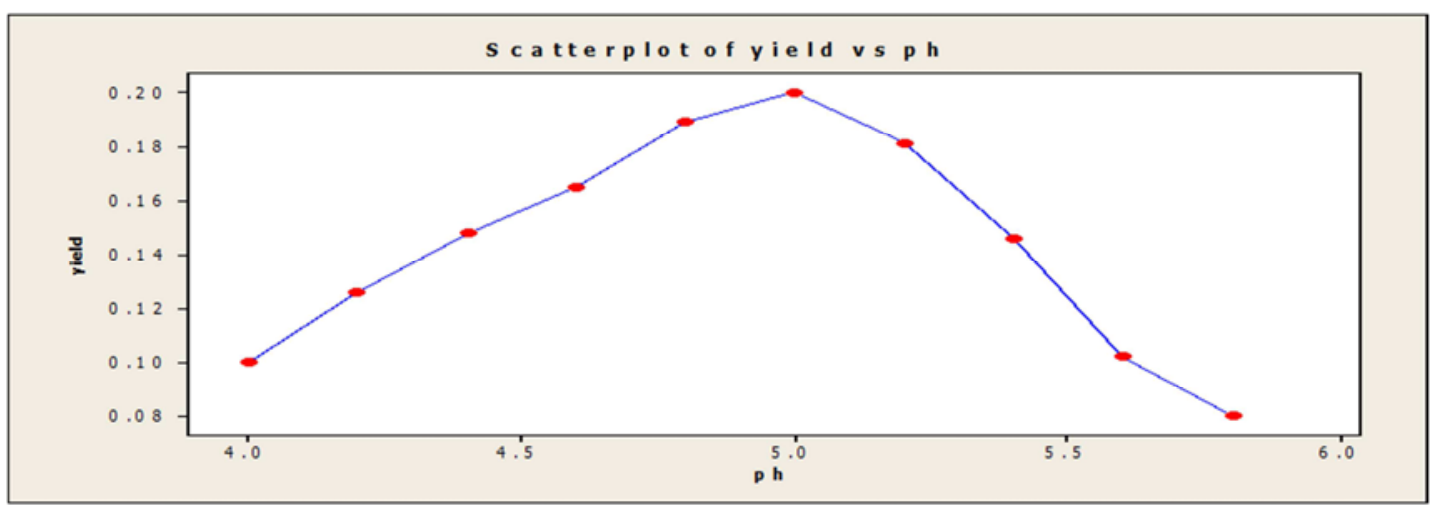

Figure 5. $p H$ variation with yield.

Yield $=-2.844+1.246 \mathrm{ph}-0.128 \mathrm{ph}^{\wedge} 2 \mathrm{R}^{2}=0.934$

t-values (-9.223) (9.804) (-9.888)

Interpretation: The relationship is explained by a quadratic model 


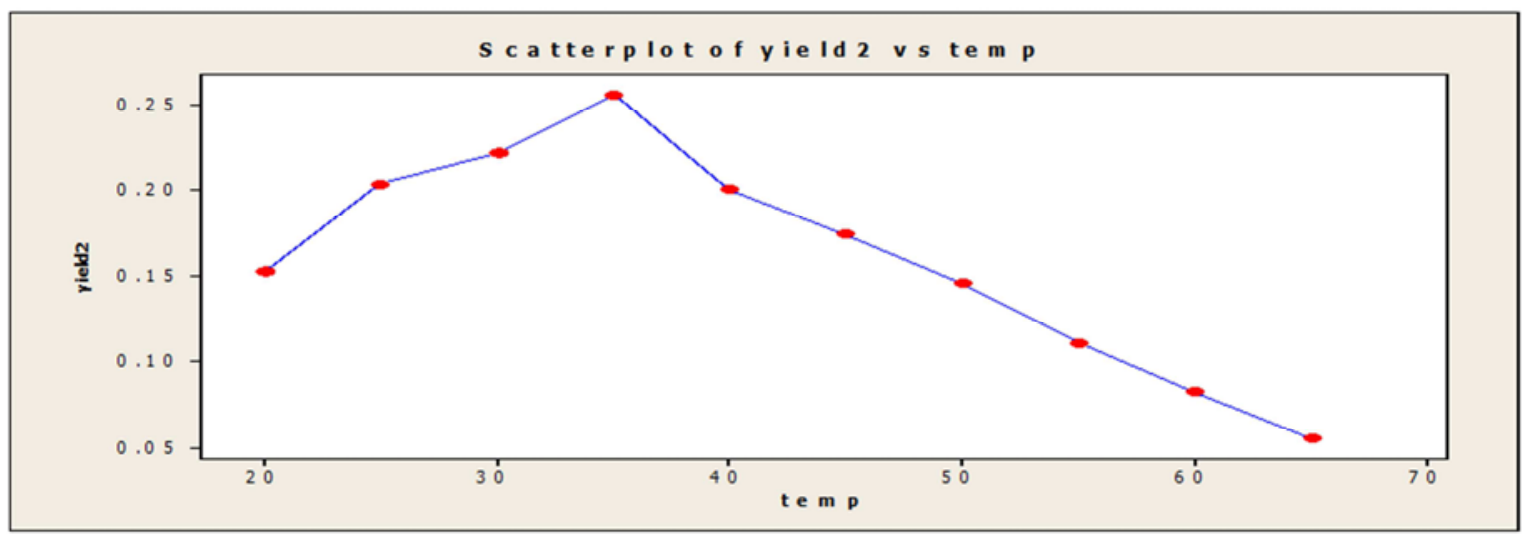

Figure 6. Temperature variation with yield.

Yield $=-0.496+0.053$ temp -0.001 temp ${ }^{\wedge}+8.12 \times 10^{-6}$ temp $^{\wedge} 3 \mathrm{R}^{2}=0.974$

t-values (-4.259) (5.744) (-5.275) (4.499)

Interpretation: The relationship is explained by a Cubic model

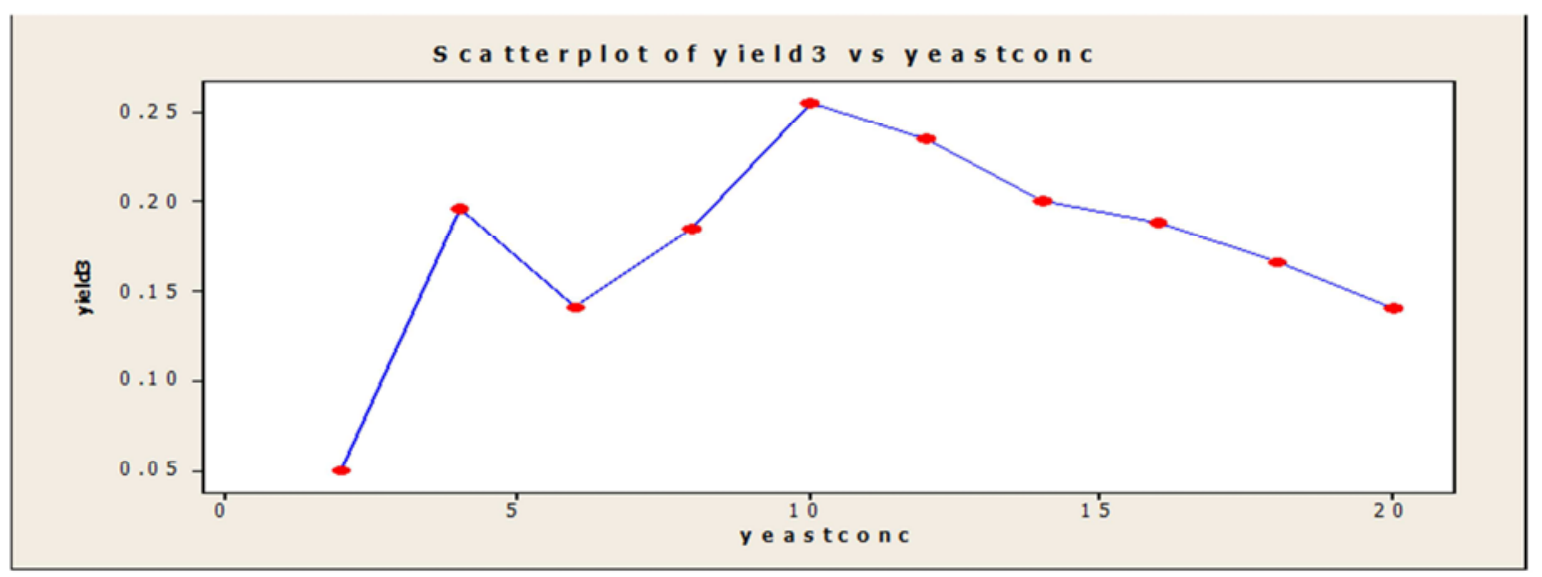

Figure 7. Yeast concentration variation with yield.

Yield $=0.015+0.036$ yeastconc -0.001 yeastconc ${ }^{\wedge} \mathrm{R}^{2}=0.719$

t-values (0.378) (4.209) (-4.002)

Interpretation: The relationship is explained by a quadratic model

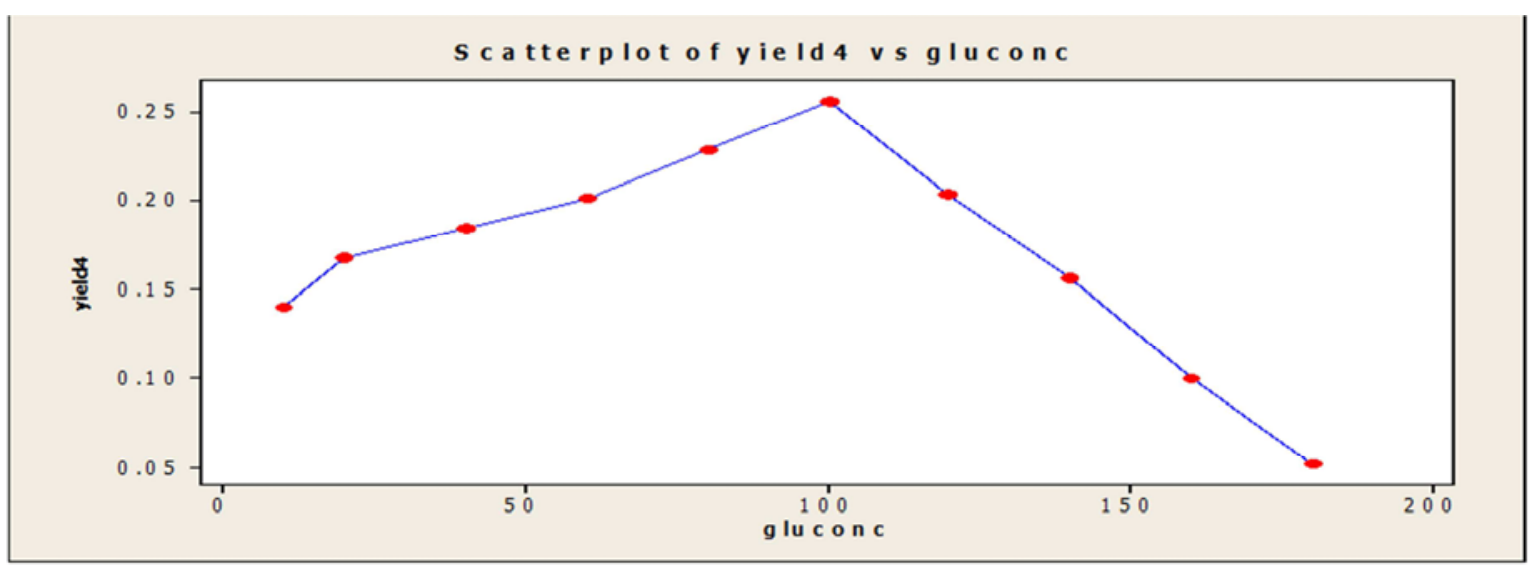

Figure 8. Glucose concentration variation with yield.

Yield $=0.0106+0.003$ gluconc $-1.9 \times 10^{-5}$ gluconc $^{\wedge} 2 \mathrm{R}^{2}=0.939$

t-values (7.013) (7.847) (-9.283)

Interpretation: The relationship is explained by a quadratic model 


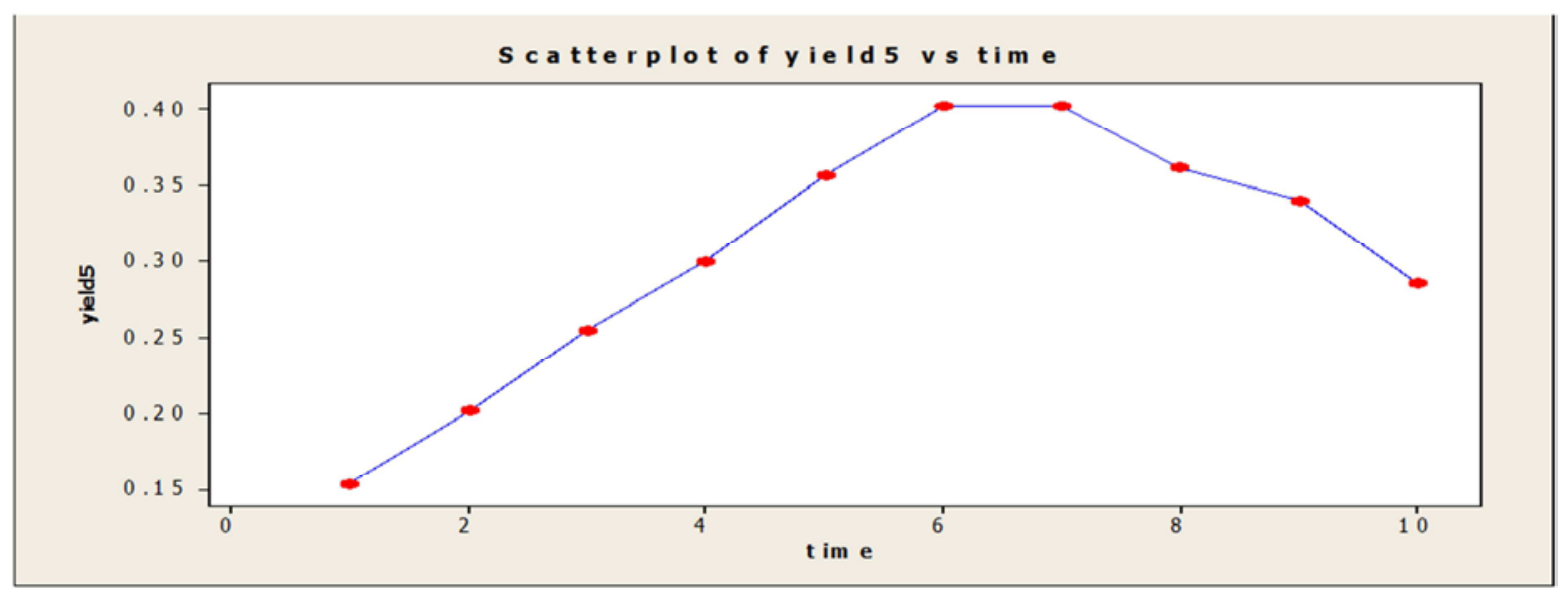

Figure 9. Time variation with yield.

Yield $=0.035+0.103$ time -0.008 time $^{\wedge} 2 \mathrm{R}^{2}=0.953$

t-values (1.457) (10.249) (-8.646)

Interpretation: The relationship is explained by a quadratic model

\subsection{Analysis of Variance for Time with Temperature Variation for Hydrolysis Process}

The ANOVA table for time with temperature variation for hydrolysis process is presented in table 2 below, while the post ANOVA result for temperature and time are presented in tables 3 and 4 respectively.

Table 2. Analysis of Variance for Time with Temperature Variation for Hydrolysis Process.

\begin{tabular}{llllll}
\hline \multicolumn{5}{l}{ Tests of Between-Subjects Effects } \\
\hline \multicolumn{2}{l}{ Dependent Variable: yield } & & & & \\
\hline Source & Type III sum of Squares & df & Mean Square & F & Sig \\
\hline Corrected Model & $8373.007^{\mathrm{a}}$ & 18 & 465.167 & 239.271 & .000 \\
Intercept & 314743.440 & 1 & 314743.440 & 161896.4 & .000 \\
Temp & 2886.488 & 9 & 320.721 & 164.971 & .000 \\
Time & 5486.520 & 9 & 609.613 & 313.570 & .000 \\
Error & 157.472 & 81 & 1.944 & & \\
Total & 323273.920 & 100 & & & \\
Corrected Total & 8530.480 & 99 & & & \\
\hline
\end{tabular}

${ }^{\text {a }}$ R Squared $=982$ (Adjusted R Squared $=977$ )

Table 3. Post Hoc Tests for temperature.

\begin{tabular}{|c|c|c|c|c|c|c|c|c|}
\hline \multicolumn{9}{|c|}{ Homogeneous Subsets } \\
\hline \multicolumn{9}{|c|}{ yield } \\
\hline \multicolumn{9}{|c|}{ Duncan $^{\text {a b }}$} \\
\hline \multirow{2}{*}{ temp } & \multirow[b]{2}{*}{$\mathbf{N}$} & \multicolumn{7}{|l|}{ Subset } \\
\hline & & 1 & 2 & 3 & 4 & 5 & 6 & 7 \\
\hline 90.00 & 10 & 45.2200 & & & & & & \\
\hline 135.00 & 10 & & 51.3700 & & & & & \\
\hline 95.00 & 10 & & 52.3900 & & & & & \\
\hline 130.00 & 10 & & & 54.4600 & & & & \\
\hline 100.00 & 10 & & & & 56.2400 & & & \\
\hline 125.00 & 10 & & & & 56.5100 & & & \\
\hline 120.00 & 10 & & & & & 58.8600 & & \\
\hline 105.00 & 10 & & & & & 59.4400 & & \\
\hline 115.00 & 10 & & & & & & 61.0500 & \\
\hline 110.00 & 10 & & & & & & & 65.4800 \\
\hline Sig & & 1.000 & .006 & 1.000 & .666 & .355 & 1.000 & 1.000 \\
\hline
\end{tabular}

Means for groups in homogeneous are displayed

Based on Type 111 Sum of Squares

The error term is Mean Square (Error) $=1.944$

${ }^{a}$ Uses Harmonic Mean Sample Size $=10.000$

${ }^{\mathrm{b}}$ Alpha $=05$ 
Table 4. Post Hoc Tests for time.

\begin{tabular}{|c|c|c|c|c|c|c|c|c|c|c|}
\hline \multicolumn{11}{|c|}{ Homogeneous Subsets } \\
\hline \multicolumn{11}{|l|}{ yield } \\
\hline \multicolumn{11}{|c|}{ Duncan $^{\text {a b }}$} \\
\hline \multirow{2}{*}{ time } & \multirow{2}{*}{$\mathbf{N}$} & \multicolumn{9}{|l|}{ Subset } \\
\hline & & 1 & 2 & 3 & 4 & 5 & 6 & 7 & 8 & 9 \\
\hline 50.00 & 10 & 41.9900 & & & & & & & & \\
\hline 45.00 & 10 & & 47.1200 & & & & & & & \\
\hline 5.00 & 10 & & & 50.2100 & & & & & & \\
\hline 40.00 & 10 & & & & 53.5300 & & & & & \\
\hline 10.00 & 10 & & & & & 56.4500 & & & & \\
\hline 15.00 & 10 & & & & & & 59.5700 & & & \\
\hline 35.00 & 10 & & & & & & 59.7500 & & & \\
\hline 20.00 & 10 & & & & & & & 62.0400 & & \\
\hline 25.00 & 10 & & & & & & & & 64.1900 & \\
\hline 30.00 & 10 & & & & & & & & & 66.1700 \\
\hline Sig & & 1.000 & 1.000 & 1.000 & 1.000 & 1.000 & 774 & 1.000 & 1.000 & 1.000 \\
\hline
\end{tabular}

Means for groups in homogeneous are displayed

Based on Type 111 Sum of Squares

The error term is Mean Square (Error) $=1.944$

${ }^{a}$ Uses Harmonic Mean Sample Size $=10.000$

${ }^{\mathrm{b}}$ Alpha $=05$

Interpretation: Time and temperature were very significant in the analysis. The yield is optimum at $110^{\circ} \mathrm{C}$ and in $30 \mathrm{mins}$.

\subsection{Analysis of Variance for Time with Temperature Variation for Fermentation Process}

The ANOVA table for time with temperature variation for fermentation process is presented in table 4 below, while the post ANOVA result for temperature and time are presented in tables 5 and 6 respectively.

Table 5. Analysis of Variance for Time with Temperature Variation for Fermentation Process.

\begin{tabular}{|c|c|c|c|c|c|}
\hline \multicolumn{6}{|c|}{ Tests of Between-Subjects Effects } \\
\hline \multicolumn{6}{|c|}{ Dependent Variable: yield 1} \\
\hline Source & Type Ill sum of Squares & df & Mean Square & $\mathbf{F}$ & Sig \\
\hline Corrected Model & $9794.198^{\mathrm{a}}$ & 18 & 544.122 & 135.303 & 000 \\
\hline Intercept & 37570.069 & 1 & 37570.069 & 9342.262 & 000 \\
\hline Temp & 6540.716 & 9 & 726.746 & 180.714 & 000 \\
\hline Time & 3253.482 & 9 & 361.498 & 89.891 & 000 \\
\hline Total & 47690.010 & 100 & & & \\
\hline Corrected Total & 10119.941 & 99 & & & \\
\hline
\end{tabular}

${ }^{\mathrm{a}} \mathrm{R}$ Squared $=968$ (Adjusted R Squared $=961$ )

Table 6. Post Hoc Tests for temperature.

\begin{tabular}{|c|c|c|c|c|c|c|c|c|c|c|}
\hline \multicolumn{11}{|c|}{ Homogeneous Subsets } \\
\hline \multicolumn{11}{|l|}{ yield1 } \\
\hline \multicolumn{11}{|c|}{ Duncan $^{\text {a b }}$} \\
\hline \multirow{2}{*}{ Time1 } & \multirow{2}{*}{$\mathbf{N}$} & \multicolumn{9}{|l|}{ Subset } \\
\hline & & 1 & 2 & 3 & 4 & 5 & 6 & 7 & 8 & 9 \\
\hline 65.00 & 10 & 5.4600 & & & & & & & & \\
\hline 60.00 & 10 & & 7.6000 & & & & & & & \\
\hline 55.00 & 10 & & & 13.5200 & & & & & & \\
\hline 50.00 & 10 & & & & 16.1100 & & & & & \\
\hline 20.00 & 10 & & & & & 19.6500 & & & & \\
\hline 45.00 & 10 & & & & & & 22.9300 & & & \\
\hline 25.00 & 10 & & & & & & 24.1400 & 24.1400 & & \\
\hline 30.00 & 10 & & & & & & & 25.9000 & & \\
\hline 40.00 & 10 & & & & & & & & 27.9500 & \\
\hline
\end{tabular}




\begin{tabular}{|c|c|c|c|c|c|c|c|c|c|c|}
\hline \multicolumn{11}{|c|}{ Homogeneous Subsets } \\
\hline \multicolumn{11}{|c|}{ yield1 } \\
\hline \multicolumn{11}{|c|}{ Duncan $^{\mathrm{a} b}$} \\
\hline \multirow{2}{*}{ Time1 } & \multirow{2}{*}{$\mathbf{N}$} & Subset & & & & & & & & \\
\hline & & 1 & 2 & 3 & 4 & 5 & 6 & 7 & 8 & 9 \\
\hline 35.00 & 10 & & & & & & & & & 30.5700 \\
\hline Sig & & 1.000 & 1.000 & 1.000 & 1.000 & 1.000 & 181 & 053 & 1.000 & 1.000 \\
\hline
\end{tabular}

Means for groups in homogeneous are displayed

Based on Type 111 Sum of Squares

The error term is Mean Square (Error) $=4.022$

${ }^{a}$ Uses Harmonic Mean Sample Size $=10.000$

${ }^{\mathrm{b}}$ Alpha $=05$

Table 7. Post Hoc Tests for time.

\begin{tabular}{|c|c|c|c|c|c|c|c|}
\hline \multicolumn{8}{|c|}{ Homogeneous Subsets } \\
\hline \multicolumn{8}{|l|}{ yield1 } \\
\hline \multicolumn{8}{|c|}{ Duncan $^{\text {a b }}$} \\
\hline \multirow{2}{*}{ Time1 } & \multirow{2}{*}{$\mathbf{N}$} & \multicolumn{6}{|l|}{ Subset } \\
\hline & & 1 & 2 & 3 & 4 & 5 & 6 \\
\hline 1.00 & 10 & 8.9200 & & & & & \\
\hline 2.00 & 10 & & 12.4600 & & & & \\
\hline 3.00 & 10 & & & 15.9200 & & & \\
\hline 10.00 & 10 & & & 15.9200 & & & \\
\hline 4.00 & 10 & & & & 19.9000 & & \\
\hline 9.00 & 10 & & & & 19.9000 & & \\
\hline 5.00 & 10 & & & & & 23.5900 & \\
\hline 8.00 & 10 & & & & & 23.8600 & \\
\hline 6.00 & 10 & & & & & & 26.6500 \\
\hline 7.00 & 10 & & & & & & 26.6500 \\
\hline Sig & & 1.000 & 1.000 & 1.000 & 947 & 764 & 1.000 \\
\hline
\end{tabular}

Means for groups in homogeneous are displayed

Based on Type 111 Sum of Squares

The error term is Mean Square (Error) $=4.022$

${ }^{a}$ Uses Harmonic Mean Sample Size $=10.000$

${ }^{\mathrm{b}}$ Alpha $=05$

Interpretation: Time and temperature were very significant in the analysis. The yield is optimum at $35^{\circ} \mathrm{C}$ and in 6 days and 7 days respectively.

\section{Discussion of Results}

Curve fitting technique and a Two factors analysis of variance (ANOVA) without interaction were used to analyze data collected during hydrolysis and fermentation processes in the production of Bioethanol from cassava peels. For hydrolysis process, temperature, Acid concentration, substrate concentration and time were varied with yield. Results revealed that fig. 1, 2 and 4 follows a quadratic model and fig. 3 was explained by linear model. While for fermentation process, $\mathrm{pH}$, Temperature, Yeast Concentration, Glucose concentration and time were varied with yield. The analysis shows that figs. 5, 7 and 9 follows quadratic model and fig. 6 follows a cubic model. Time and temperature were very significant in the production of Bioethanol from cassava peels. For hydrolysis process, yield is optimum at $110^{\circ} \mathrm{C}$ and in $30 \mathrm{mins}$, while for fermentation process yield is optimum at $35^{\circ} \mathrm{C}$ and in 6 days and 7 days respectively.

\section{Conclusion}

This present work therefore concludes that linear, cubic and quadratic models can be used to predict yield for both hydrolysis and fermentation process. Bioethanol yield is optimum at $110^{\circ} \mathrm{C}$ and in $30 \mathrm{mins}$ for hydrolysis process, while yield is optimum at $35^{\circ} \mathrm{C}$ and in 6days and 7 days respectively for fermentation process.

\section{References}

[1] Adesanya, O; Oluyemi, K; Josiah, S; Adesanya, R; Shittu, L; Ofusori, D; Bankole, M \& Babalola, G. (2007): Ethanol Production by Saccharomyces Cerevisiae from Cassava Peel Hydrolysate. The Internet Journal of Microbiology, 5(1): 1-5.

[2] Archibong, E. J; Obika, I. E; Okafor, O. I; Okafor, U. I.; Ezewuzie, C. S; Ezemba, C. C; Awah, N. C; Okeke, B. C; Anaukwu, G. C. \&Anakwenze, V. N. (2016): Ethanol Production from Cassava Waste (Pulp and Peel) Using Alcohol Tolerant Yeast Isolated from Palm Wine. American Journal of Life Science Research, 4(3): 92-97. 
[3] Kongkiattikajorn, J. \& Sornvoraweat, B. (2011): Comparative Study of Bioethanol Production from Cassava Peels by Monoculture and Co-Culture of Yeast. Kasetsart J. (Nat. Sci.) 45: 268-274.

[4] Das, M. N. and Giri, N. C. (1986). Design and Analysis of Experiments $\left(2^{\text {nd }} E d\right)$. Indian: New Age International (p) Ltd publishers.

[5] Coope, I. D. (1993). Circle fitting by linear and non linear least squares. Journal of optimization theory and Application. 76(2). New York: Plenum Press.

[6] Press, W. H., Flannery, B. P., Teukolsky, S. A. and Vertterling, W. T. (1988). Numerical Recipes in C. New York: Cambridge University Press.

[7] Chang, B and Shao, C. (2006). Testing treatment effects in two-way linear models: Additive or Full model? Sankhya: the Indian Journal of Statistics. 68(3). Pp. 392-408

[8] Lingren, B. W., McElrath, G. W. and Berry, D. A. (1978). Introduction to probability and Statistics $\left(4^{\text {th }}\right.$ Ed). New York: Macmillan Publishing Co Inc.

[9] Akponah, E. (2011): Production of Ethanol from Cassava (Mannihot esculenta) Waste Water Using Saccharomyces Cerevisiae and Eucherichia coli. Nig. J. Micro, 25: 2369-2378.

[10] Nuwannanya, E; Chiwona-Karltun, L; Kawuki, R. S. \& Baguma, Y. (2012): Bio-Ethanol Production from Non-Food Parts of Cassava (Manihot esculenta Crantz). AMBIO, 41: 262-270.

[11] Ajibola, F. O; Edema, M. O. \& Oyewole, O. B. (2012): Enzymatic Production of Ethanol from Cassava Starch Using Two Strains of Saccharomyces Cerevisiae. NIFOJ, 30(2): 114121.
[12] Oyeleke, S. B; Dauda, B. E. N; Oyewole, O. A; Okoliegbe, I. N. \& Ojebode, T. (2012): Production of Bioethanol from Cassava and Sweet Potato Peels. Advances in Environmental Biology, 6(1): 241-245.

[13] Mohammed, A; Oyeleke, S. B. \& Egwim, E. C. (2014): Pretreatment and Hydrolysis of Cassava Peels for Fermentable Sugar Production. Asian Journal of Biochemistry, 9(1): 65-70.

[14] Abidin, Z; Saraswati, E. \& Naid, T. (2014): Bioethanol Production from Waste of the Cassava Peel (Manihot esculenta) by Acid Hydrolysis and Fermentation Process. Intl J. PharmTech Research, 6(4): 1209-1212.

[15] Adiotomre, K. O. (2015): Production of Bioethanol as an Alternative Source of Fuel Using Cassava and Yams Peels as Raw Materials. Intl J. Inno Sci. \& Eng'g, 3(2): 28-44.

[16] Chibuzor, O; Uyoh, E. A. \& Igile, G. (2016): Bioethanol Production from Cassava Peels Using Different Microbial Inoculants. African Journal of Biotechnology, 15(30): 16081612 .

[17] Beyer, W. H. (1976). Standard Mathematical Tables. Cleveland: CRC Press.

[18] Nelson, P. R., Coffin, M and Copeland K. A. F. (2003). Introduction Statistics for Engineering Experimentation. USA: Elsevier Academic Press.

[19] Oyejola, B. A. (2003). Design and Analysis of Experiment for Biology and Agriculture Students. Nigeria: Olad publisher.

[20] Zar, J H. (1999). Biostatistical Analysis (4 ${ }^{\text {th }}$ Ed). Indian: Dorling Kindersley Pvt Ltd. 